\title{
DISTRIBUTION OF THE LEGALLY PROTECTED LICHEN SPECIES CETRARIA ISLANDICA IN HUNGARY
}

\author{
Mónika SiNIGLA ${ }^{1 *}$, László Lö Kös ${ }^{2}$, Nóra VARGA ${ }^{3}$ and Edit FARKAs ${ }^{3}$ \\ ${ }^{1}$ Bakony Natural History Museum, Hungarian Natural History Museum \\ H-8420 Zirc, Rákóczi tér 3-5. Hungary; *inigla@nbmus.hu \\ ${ }^{2}$ Department of Botany, Hungarian Natural History Museum, H-1476 Budapest, Pf. 222. Hungary \\ ${ }^{3}$ Institute of Ecology and Botany, Centre for Ecological Research, Hungarian Academy of Sciences, \\ H-2163 Vácrátót, Alkotmány u. 2-4. Hungary
}

Sinigla, M., Lőkös, L., Varga, N. \& Farkas, E. (2015): Distribution of the legally protected lichen species Cetraria islandica in Hungary. - Studia bot. hung. 46(1): 91-100.

\begin{abstract}
Cetraria islandica is a rare lichen species with 20 known localities in Hungary. It became legally protected in Hungary in 2013. However, its distribution, habitat preferences and population dynamical conditions are insufficiently known and the species is still regarded as rare. The species is discussed on the basis of its Hungarian representatives and the so far revealed localities are presented on an updated distribution map.
\end{abstract}

Key words: Cetraria islandica, floristical records, Hungary, legally protected, lichen-forming fungi

\section{INTRODUCTION}

Cetraria islandica (L.) Ach. (Parmeliaceae, Lecanorales, Ascomycota) is a cosmopolitan, extremely successful, morphologically very variable, fruticose, terricolous lichen species (Fig. 1). In Europe it is primarily distributed in the coniferous zone, in arctic-alpine, boreal-montane habitats; and also occurs in various secondary habitats, ranging from acid heathlands to calcareous rocky grasslands (KärNefELt 1979, Nimis and MARTEllos 2004). It forms continuous, dense, dark brown carpet on the soil, or scattered smaller patches growing together with terricolous bryophytes and lichens.

Cetraria islandica (the Iceland Moss) was extensively used as a drug in folk medicine against lung diseases, catarrh and diabetes in older times in Hungary and it is used even today in some other countries (SCHOLz 2004). This species is also popular in cosmetic industry, e.g. as a component of skin care creams. Its medicinal usage was concerned and cited several times in most Hungarian medicinal plant literature as well: Augustin et al. 1948, Dietl 1854, Diószegi 1813, Gallé 1975, Halmai and Novák 1963, Petri 1991, Rácz et al. 1984, RápóTI and RomVÁry 1977, RÉTHY 2004, VÁrady 1982, VARRó 1926, 1941, 1991, Verzárné-Petri 1979, 1982, Verzárné-Petri et al. 1984, 1989). It was also 
included and recommended as a drug (called Lichen islandicus) in the first five editions of the official Hungarian Medicine Catalogue (Ph.Hg. 1871, 1888, 1909, 1933, 1954, Mi Kó 1936). It was omitted in two subsequent editions (Ph.Hg. 1967, 1986) probably because of its diminishing importance. Recently, it became again fashionable, and the drug was included in the latest edition (Ph.Hg. 2003-2006). However, neither these publications nor other literature (ANONYMOUS 1981, BALOGH 1837, Boros 1940, Gallé 1959, SÁRKÁNY and SZALAI 1966) provide information on the circumstances, localities, quantity or frequency of collecting (Fig. 2) or the former collecting sites in Hungary.

The oldest Hungarian Cetraria islandica specimens, deposited in the lichen herbarium of the Hungarian Natural History Museum (BP), originate from the 19th century from the Résely's collection. One of them (collected from the Bakony Mts) dates back to 1861 (Fig. 3), the other one (collected from the Sopron Mts) has no date indication (Fig. 4). These specimens, however, were not cited by F. Hazslinszky in his account of the lichen flora (HAzsLINSz KY 1884).

A remarkable locality was discovered by F. Fóriss in the Buda Mts (NagyKopasz Hill) at the beginning of the last century (1912). This locality was overexploited by Gy. Timkó, who issued the specimens in the famous Flora Hungarica

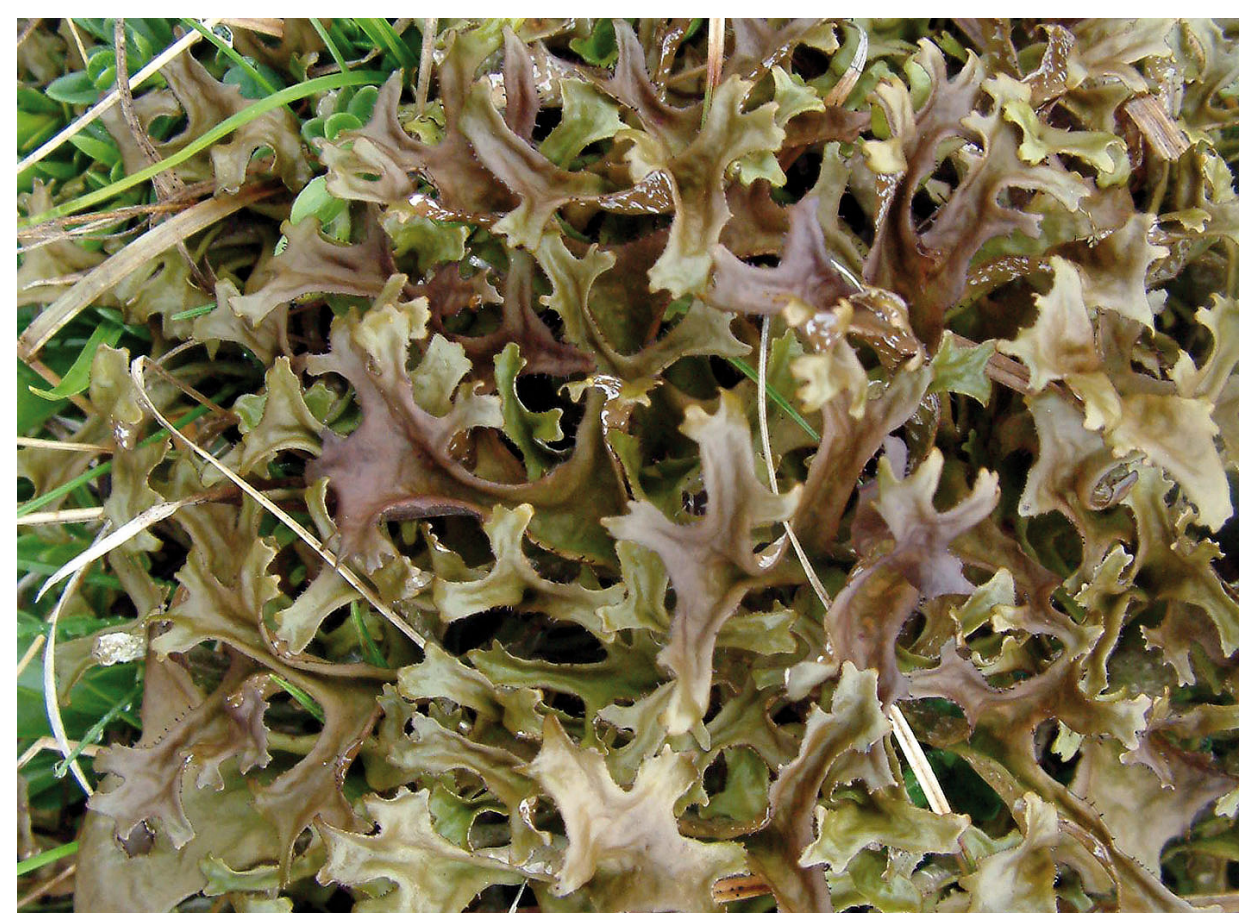

Fig. 1. General terricolous habit of Cetraria islandica. 
Exsiccata (Fig. 5). Later F. Fóriss found two additional localities in 1914 (PilisVisegrád Mts) and 1939 (Bükk Mts), and Á. Boros, the famous Hungarian bryologist, spotted three more (Pilis-Visegrád Mts (2), Transdanubian Hills). Unfortunately, no voucher specimens were found for literature records from the coenological relevé of G. Vida from West Hungary (JA KUCs 1965), and from two localities in the Mátra Mts (KIsZelyné-VÁmosi 1983).

Based on the above records Cetraria islandica was assumed as an existing, but a strongly vanishing species in the Hungarian lichen biota (VERSEGHY 1994).

Recent localities were discovered in western Hungary in 1983 by T. Kiss and G. Facsar; in the Vendvidék region in 1994 (Löкös and FARKAS 1998); in the Aggtelek National Park between 1994 and 1999 (Löкös 2009); and in the Bakony Mts in 2010 and 2013 by M. Sinigla.

Considering the new occurrences Cetraria islandica was evaluated as endangered in the red list of the Hungarian lichen-forming fungi (LöKös and Tó TH 1997).

The aim of this study is to present a current Hungarian distribution map of Cetraria islandica based on the revision of all available historical and recently found specimens, and to summarise all relevant information for later nature conservational purposes.

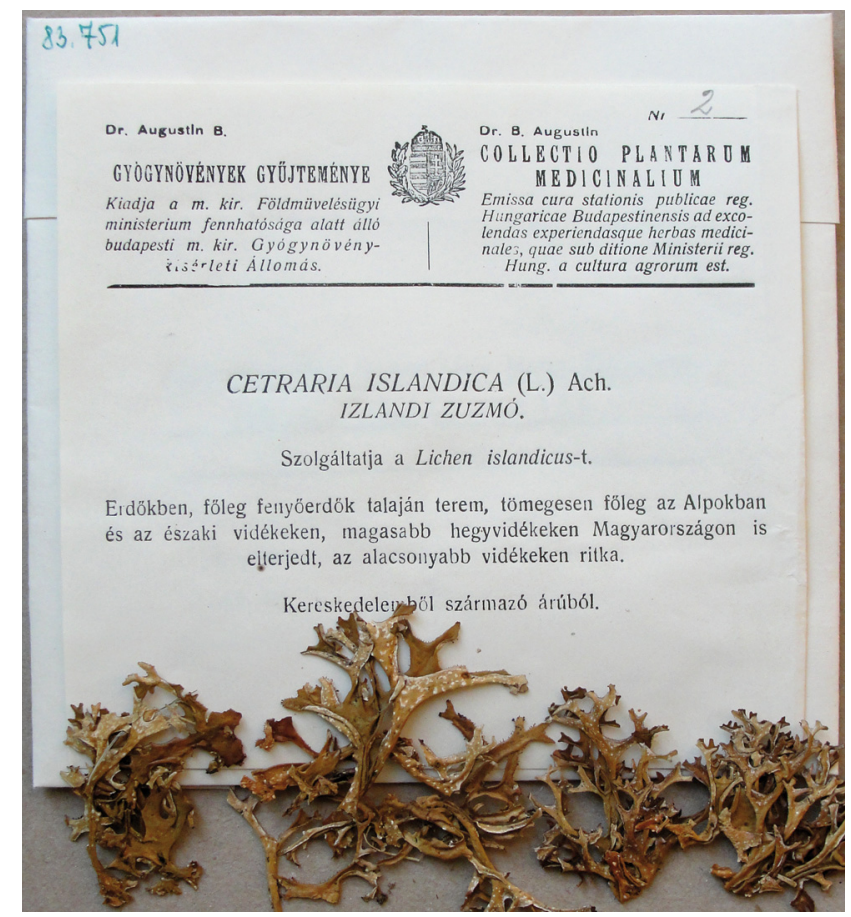

Fig. 2. Commercial Cetraria islandica specimen for medicinal purpose. 


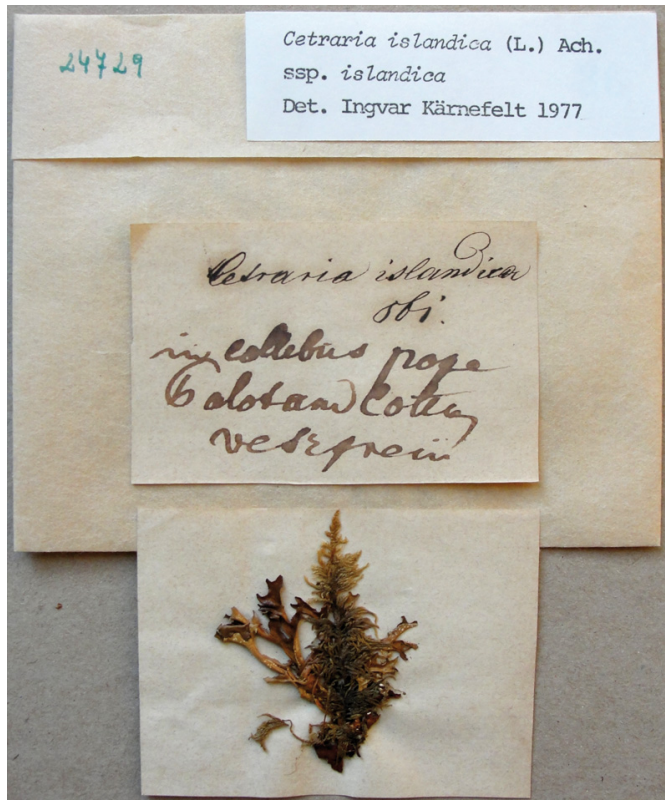

Fig. 3. Historical Cetraria islandica specimen collected by M. Résely in the Bakony Mts (Hungary) in 1861 ("in collibus prope Palotam Cottus Veszprem").

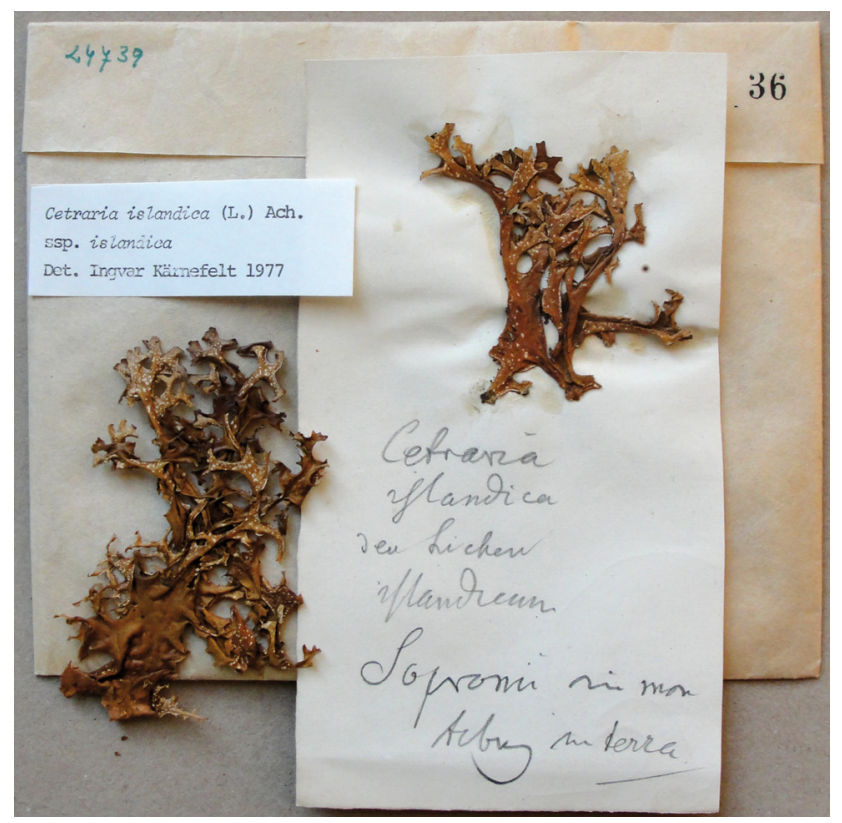

Fig. 4. Historical Cetraria islandica specimen collected by M. Résely in the Sopron Mts (Hungary) in the second half of the 19th century ("Sopronii in montibus arborea"). 


\section{MATERIAL AND METHODS}

Herbarium specimens were studied from the following Hungarian herbaria: BP, EGR, SZE, SZO. Collections made after 2005 have been deposited in herbaria BP and BTM. Herbarium acronyms follow the Index Herbariorum online (ThIERs 2015) with the exceptions of BTM (Bakony Natural History Museum of the Hungarian Natural History Museum, Zirc), and SZO (Savaria Museum, Szombathely).

Chemical substances (fumarprotocetraric and lichesterinic acid) were checked with PD spot tests and HPTLC analysis in solvent system C (ARUP et al. 1993).

The distribution map was constructed using the computer program for geographical information system, QGIS 2.6 (Brighton, 2014), where grid cells of 5 $\mathrm{km} \times 6 \mathrm{~km}$ follow the Central European mapping system (cf. Ni KLFELD 1971). Locality data recorded after 2005 have been measured by Garmin Etrex Vista C GPS (WGS 84).

\section{RESULTS AND DISCUSSION}

Altogether 22 herbarium specimens and 6 records from the literature or field have been accumulated from 20 localities (16 grid cells in Fig. 6) (Appendix 1).

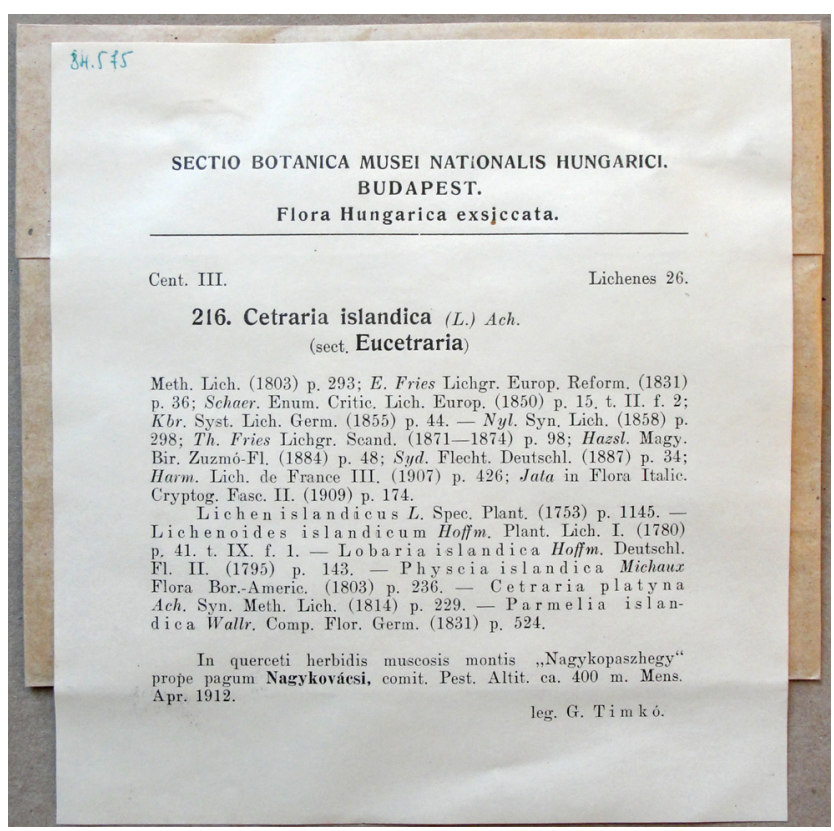

Fig. 5. Cetraria islandica specimen from the Buda Mts (Hungary) issued in the Flora Hungarica Exsiccata. 
Old localities discovered before 1975, incl. Bakony Mts (near Várpalota), Buda Mts, Bükk, Kőszeg Mts, Pilis-Visegrád Mts, Sopron Mts, Belső-Somogy, and Vasi-Hegyhát have been revisited several times without any success. More recent collecting sites (Bakony Mts (Ódörögd) - 2006; Mátra Mts - 1983, Vasi-Hegyhát - 1983) have also been checked, but the exact sampling locations could not be found ("?" in Fig. 6). According to our observations the population in the Börzsöny Mts seems to be decreasing during the last decade. No information is available on the current condition of the population in the Aggtelek National Park and in the Vendvidék region. The population, recently discovered in a very disturbed (grazed by sheep) habitat in the Bakony Mts (Taliándörögd) is also rather small consisting of trampled and more or less damaged individuals. Therefore, considering the rarity of this species in Hungary it was proposed for protection by law in 2003, but due to some commercial rules it became legally protected finally in 2013 (MK 2013).

In Hungary C. islandica occupies predominantly open habitats, mostly rocky grasslands (acid or calcareous) at low elevation (between 160 and $700 \mathrm{~m}$ a.s.l.). The occurrence of this species is rather sporadic and unstable; and bigger, continuous carpets are not known in the country. Since the Hungarian localities are very different from the usual primary habitats of the species (i.e. arctic-alpine, boreal-montane coniferous zone), they are considered as secondary habitats.

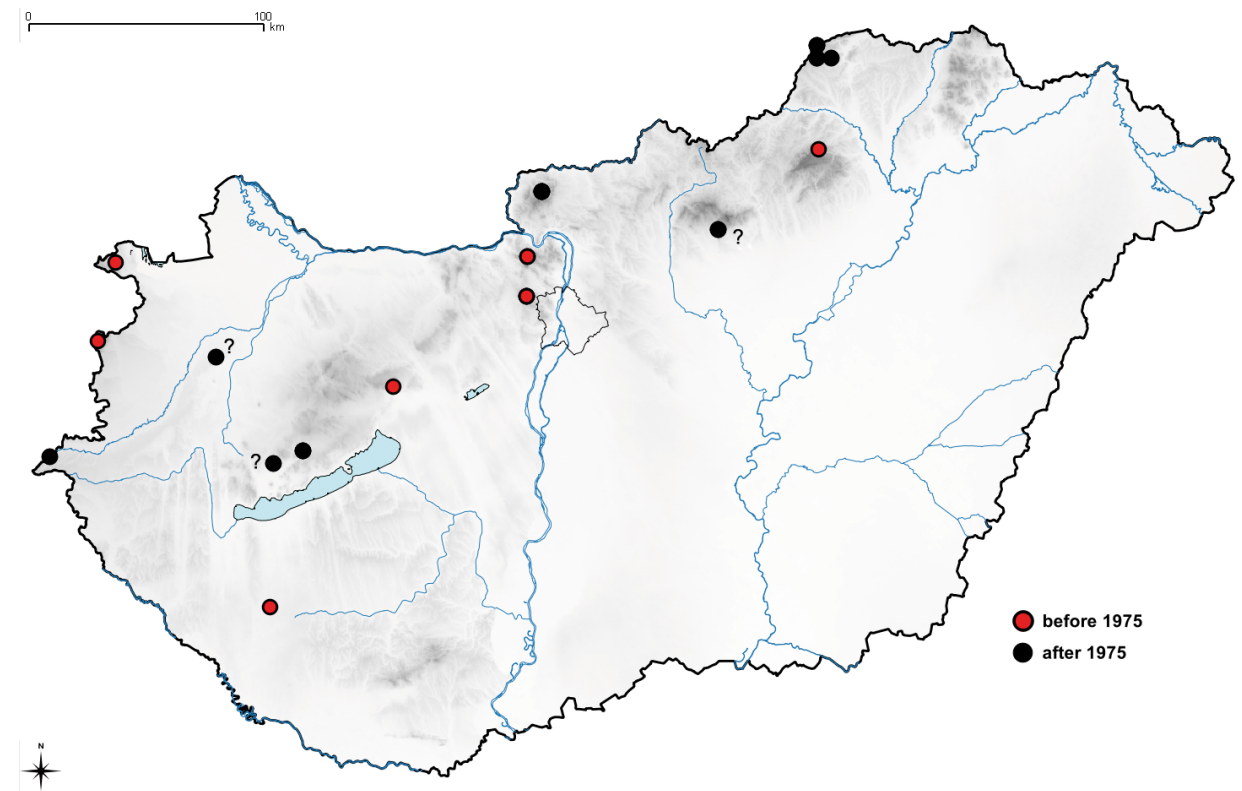

Fig. 6. Hungarian distribution of Cetraria islandica. 
In his monograph on the brown fruticose Cetraria species KäRNEFELT (1979) pointed out that in secondary habitats the metabolism, sexual reproduction and morphological development of Cetraria islandica are often influenced by environmental stress. For example several populations growing in secondary habitats were found to be deficient in fumarprotocetraric acid. However, all Hungarian specimens contained fumarprotocetraric acid.

The origin of the Hungarian populations is unknown (glacial relict or not), but further molecular genetic or phylogeographical studies might give more satisfactory explanations. The question remains open.

However, we suppose that this species will disappear from Hungary due to climate changes (global warming), judging from the tendencies shown in its former localities. It should be a great challenge for the nature conservation authorities to check the populations regularly to ensure a more effective protection and maintenance of this species.

Acknowledgements - This work was supported by the Aggtelek National Park, and the Hungarian Scientific Research Fund (OTKA K81232). We are especially grateful to Henriett Hajnal, Hajnalka Lóth, Katalin Molnár, Lajos Somlyay, Leif Tibell and Erika Tóth for their help in the field expeditions.

Összefoglaló: Az izlandi zuzmó (Cetraria islandica) 2013-ban kapott törvényes oltalmat Magyarországon. Mintegy 20 régi és újabb lelőhelye ismert, ritkasága miatt a magyarországi zuzmó vörös listában veszélyeztetett státust kapott. Szakirodalmi és herbáriumi források alapján elkészítettük az izlandi zuzmó aktuális magyarországi elterjedési térképét, a régi lelőhelyek felkeresésével megpróbáltunk további információkat gyűjteni még létező populációinak állapotáról a természetvédelem számára.

\section{REFERENCES}

Anonymous (1981): Izlandi zuzmó drog (Lichen islandicus). - MSZ 14447-81 (Magyar Szabvány). ARUP, U., EKMAN, S., LindBlom, L. and MATtsson, J. (1993): High performance thin layer chromatography (HPTLC), an improved technique for screening lichen substances. - Lichenologist 25: 61-71. http://dx.doi.org/10.1006/lich.1993.1018

Augustin, B., Jávorka, S., Giovannini, R. and Rom, P. (1948): Magyar gyógynövények. I-II. Földművelésügyi Minisztérium, Budapest, $494 \mathrm{pp}$.

BALOGH, K. (1879): A Magyar Gyógyszerkönyv kommentárja. Gyógyszertani Kézikönyv. I-II. - Eggenberger, Budapest, LXXIV + $1172 \mathrm{pp}$.

BAlogh, P. (1837): Renard. Histoire naturelle, chimique et medicale du lichen d'Islande. Paris, 1836. - Tudománytár 1: 238.

Boros, Á. (1925): A drávabalparti sikság Flórájának alapvonásai, különös tekintettel a lápokra. (Grundzüge der Flora der linken Drauebene mit besonderer Berücksichtigung der Moore). Magyar Bot. Lapok 23: 1-56 (1924).

Boros, Á. (1940): A visszacsatolt területek gyógynövénykincsei. - Herba, ser. nov. 1(2): 24-30.

DietL, A. (1854): Die isländische Flechte und deren Benützung. - Österr. Bot. Wochenbl. 4(1): 11. 
Diószegi, S. (1813): Orvosi Füvész Könyv, mint a 'Magyar Füvész Könyv' praktika része. - Csáthy György, Debreczen, 396 pp.

FHE (1914): Schedae ad "Floram Hungaricam exsiccatam", a sectione botanica Musei Nationalis Hungarici editam. Cent. III, No. 216. - Fritz Ármin Könyvnyomdája, Budapest, 48 pp.

GALLÉ, L. (1959): Antibiotikumok zuzmókban. - Élövilág 4(4): 20-23.

GALLÉ, L. (1975): A Magyar Füvészkönyv zuzmói. (Die Flechten des ungarischen Kräuterbuches). - A debreceni Déri Múz. Évk. 1974: 171-176.

Halmai, J. and Novák, I. (1963): Farmakognózia. - Medicina, Budapest, 718 pp.

Hazslinszky, F. (1884): A Magyar Birodalom zuzmó-flórája. [The lichen flora of the Hungarian Empire]. - K. M. Term. Tud. Társ., Budapest, 304 pp.

JAKUCs, P. (1965): Adatok a Köszegi-hegység savanyú talajú tölgyeseinek cönológiai viszonyaihoz. Manuscript, Budapest.

KäRNEFELT, I. (1979): The brown fruticose species of Cetraria. - Opera botanica 46: 1-150.

Kiszelyné-VÁmosi, A. (1983): A Mátra-hegység zuzmóflórája II. (Lichen flora of the Mátra Mountains, Part II). - Folia Hist.-nat. Mus. Matr. 8: 63-75 (1982-1983).

LöKös, L. (2009): The lichen-forming fungi of the Aggtelek National Park (NE Hungary). - In: PAPP, B. (ed.): Flora of the Aggtelek National Park. Cryptogams. Hungarian Natural History Museum, Budapest, pp. 109-174.

LöKös, L. and FARKAS, E. (1998): Az Örség zuzmóflórájának alapvetése. (The lichen flora of Örség, Western Hungary). - Savaria, a Vas megyei Múz. Ért. 24(2): 127-160.

Löкӧs, L. and Tóтн, Е. (1997): Red list of lichens of Hungary (a proposal). - In: Tóтн, E. and Horváth, R. (eds): Proceedings of the "Research, Conservation, Management" Conference, Aggtelek, Hungary, 1-5 May 1996. Vol. I, pp. 337-343.

Löкös, L., Tótн, Z. and BALOGH, L. (1997): A Köszegi-hegység zuzmóflórája. - Tilia 5: 7-93.

Mı Kó, Gy. (1936): A IV.-ik Magyar Gyógyszerkönyv Kommentárja. - Pannonia Könyvnyomda Vállalat, Debrecen, $639 \mathrm{pp}$.

MK (2013): 83/2013. (IX. 25.) VM rendelet. A védett és a fokozottan védett növény- és állatfajokról, a fokozottan védett barlangok köréről, valamint az Európai Közösségben természetvédelmi szempontból jelentős növény- és állatfajok közzétételéről szóló 13/2001. (V. 9.) KöM rendelet módosításáról. - Magyar Közlöny 2013(156): 67479-67503. (2013. szeptember 25).

Niklfeld, H. (1971): Bericht über die Kartierung der Flora Mitteleuropas. - Taxon 20: 545-571. http://dx.doi.org/10.2307/1218258

Nimis, P. L. and MARTEllos, S. (2004): Keys to the lichens of Italy. I. Terricolous species. - Le Guide di Dryades 1, Serie Licheni I (L-I), Edizioni Goliardiche, Trieste, 341 pp.

Petri, G. (1991): Gyógynövény-és drogismeret. 2. ed. (bővített, átdolg.). - Medicina, Budapest, 399 pp.

Ph.Hg. (1871): Magyar gyógyszerkönyv (Pharmacopoea Hungarica), 1. ed. - Pesti Könyvnyomdarészvény-társulat, Budapest, XXXXVI + $581 \mathrm{pp} .+55 \mathrm{pp}$.

Ph.Hg. (1888): Magyar gyógyszerkönyv (Pharmacopoea Hungarica), 2. ed. - Athenaeum R. Társ. könyvnyomdája, Budapest, XLV + 716 pp.

Ph.Hg. (1909): Magyar gyógyszerkönyv (Pharmacopoea Hungarica), 3. ed. - M. Kir. Állami Nyomda, Budapest, XX + 414 pp., XIII + 430 pp.

Ph.Hg. (1933): Magyar gyógyszerkönyv (Pharmacopoea Hungarica), 4. ed. - Magyar Királyi Állami Nyomda, Budapest, 424 pp., 419 pp.

Ph.Hg. (1954): Magyar gyógyszerkönyv (Pharmacopoea Hungarica), I-III, 5. ed. - Egészségügyi Kiadó, Budapest, 1627 pp.

Ph.Hg. (1967): Magyar gyógyszerkönyv (Pharmacopoea Hungarica), I-III, 6. ed. - Medicina Könyvkiadó, Budapest, XLIV + 1545 pp.

Ph.Hg. (1986): Magyar gyógyszerkönyv (Pharmacopoea Hungarica), I-IV, 7. ed. - Medicina Könyvkiadó, Budapest, 2206 pp. 
Ph.Hg. (2003-2006): Magyar gyógyszerkönyv (Pharmacopoea Hungarica), I-IV, 8. ed. - Medicina Könyvkiadó Zrt., Országos Gyógyszerészeti Intézet, Budapest, 8581 pp.

RÁcz, G., RÁcz-Kotilla, E. and LAZA, A. (1984): Gyógynövényismeret. - Ceres Könyvkiadó, Bukarest, $288 \mathrm{pp}$.

RÁPóti, J. and RomvÁRY, V. (1977): Gyógyitó növények. - Medicina Könyvkiadó, Budapest, 511 pp.

RÉTHy, Zs. (2004): A zuzmók fitoterápiás értékelése, különös tekintettel a Cetraria islandica-ra. Diplomadolgozat, Semmelweis Egyetem, Farmakognóziai Intézet, 47 pp.

SÁRKÁNY, S. and SzAlaI, I. (1966): Növénytani praktikum I. Növényszervezettani gyakorlatok. Tankönyvkiadó Vállalat, Budapest, 707 pp.

Scholz, P. (2004): Uses of lichens: 1. Isla-Moos and Isla-Mint herbal lozenges. - Intern. Lichenol. Newsl. 37(2): 16-17.

Thiers, B. (2015, continuously updated): Index Herbariorum: a global directory of public herbaria and associated staff. - New York Botanical Garden's Virtual Herbarium. http://sweetgum. nybg.org/ih/. [accessed: 10 January 2015]

Tiм Kó, Gy. (1925): Új adatok a Budai és Szentendre-Visegrádi hegyvidék zuzmóvegetációjának ismeretéhez. (Neue Beitrage zur Kenntnis der Flechtenvegetation des Buda-Szentendre-Visegráder Gebirges). - Bot. Közlem. 22: 81-104.

VÁrady, J. (1982): Drogismeret. 3. ed. - Mediána Könyvkiadó, Budapest, 159 pp.

VARró, A. B. (1926): Gyógynövények mint háziszerek. A phytotherapia népies ismertetése. - Tisza Testvérek Könyvkereskedés, Budapest, 252 pp.

VARró, A. B. (1941): Gyógynövények gyógyhatásai. Növényi gyógyszerek. - Novák Rudolf és társa Tudományos Könyvkiadóvállalat és orvosi szakkönyvkereskedés, Budapest, 391 pp.

VARRó, A. B. (1991): Gyógynövények gyógyhatásai. - Pannon Könyvkiadó, Budapest, 261 pp.

VERSEGHY, K. (1994): Magyarország zuzmóflórájának kézikönyve. [The lichen flora of Hungary]. Magyar Természettudományi Múzeum, Budapest, 415 pp.

VerZÁRnÉ-PeTRI, G. (1979): Drogatlasz (drogok mikroszkópos vizsgálata). - Medicina Könyvkiadó, Budapest, $391 \mathrm{pp}$.

Verzárné-Petri, G. (1982): Farmakognózia. - Medicina Könyvkiadó, Budapest, 362 pp.

Verzárné-Petri, G., Nyiredyné Mikita, K. and Nyiredy, Sz. (1984): Gyógynövények a gyógyászatban. - Medicina Könyvkiadó, Budapest, (Aesculap), 287 pp.

Verzárné-Petri, G., Nyiredyné Mikita, K. and Nyiredy, Sz. (1989): Gyógynövények korszerü terápiás alkalmazása. - Medicina Könyvkiadó, Budapest, (Aesculap), 259 pp.

(submitted: 10.02.2015, accepted: 14.05 .2015$)$

\section{Appendix 1. List of localities}

Data of the herbarium specimens are given with the original texts of the labels followed by herbarium acronyms and reference numbers in brackets. Literature references are in square brackets usually at the end of the records. Observations without voucher specimens are indicated with "Obs.:".

Aggtelek National Park: Aggtelek: Szár-hegy Ny-i oldalán, Béke-barlanghoz vezető út mentén. Alt.: ca. 350 m s. m. Leg.: Tóth, E. (20.03.1994) (BP) [LöKös 2009]. - Aggtelek: Ravaszlyuk víznyelő melletti töbörben. Alt. ca. $350 \mathrm{~m} \mathrm{~s}$. m. Leg.: Tóth, E. (08.04.1994) (BP) [Löкös 2009]. - Aggtelek: Haragistya, a határ melletti töbörben a 19-es határkarónál. Leg.: Lőkös, L. (21.04.1999) (BP) [LöKös 2009]. - Jósvafö: Fertős-tető, töbör szélén. Leg.: Lőkös, L. (23.04.1999) (BP) [Löкӧs 2009]. - Varbóc: Borház-tető, TV-torony környékén. Leg.: Lőkös, L., Somlyay, L. and Tóth, E. (11.06.1998) (BP) [Lö Kös 2009]. 
Bakony Mts: in collibus prope Palotam Cottus Veszprém. Leg.: Résely, M.(?) (1861) (BP 24729). - Nyirád és Zalahaláp között, az Ódörögdi katonai lőtér területén. Leg.: Lóth, H., 2006. (BP). - Comit. Veszprém, ad terram, in graminosis siccis montis "Baksa-hegy", prope pag. Taliándörögd. Lat.: 46 59’ 07.68” N; Long.: 17 34’ 59.02” E; Alt. cca. 260 m. s. m. Leg.: Sinigla M., 05.06.2013 (BTM 000681). - Comit. Veszprém, ad terram, in graminosis siccis montis "Baksa-hegy", prope pag. Taliándörögd. Lat.: 46 59’ 07.66” N; Long.: $17^{\circ} 35^{\prime} 02.80^{\prime \prime}$ E; Alt. cca. 172 m. s. m. Leg.: Sinigla M., 14. 11.2013 (BTM 000682).

Börzsöny Mts: Börzsöny hg.: Mánna hegy, sziklás gerincen. Leg.: Moldvai, R. (09.10.1960) (BP 33574) (rev. Kärnefelt 1977) [Verseghy 1994]. - Diósjenő: Nagy-Mána É-i oldalán, a piros turistajel mentén, ca 460-500 m s. m. Leg.: Farkas, E., Lőkös, L. and Hajnal, H. (14.07.1994) (BP); the same locality. Lat.: $47^{\circ} 58^{\prime} 35.52^{\prime \prime} \mathrm{N}$; Long.: $18^{\circ} 58^{\prime} 11.16^{\prime \prime} \mathrm{E}$; Alt.: $475 \mathrm{~m}$ a.s.l. Leg.: Lökös, L. (29.07.2002) (BP); the same locality. Lat.: $47^{\circ} 58^{\prime} 32.98^{\prime \prime} \mathrm{N}$; Long.: $18^{\circ} 58^{\prime} 12.78^{\prime \prime}$ E; Alt.: $495 \mathrm{~m}$ a.s.l. Obs.: Farkas, E., Lőkös, L., Molnár, K. (07.05.2011).

Buda Mts: In querceti herbidis muscosis montis "Nagykopaszhegy" prope pagum Nagykovácsi, comit. Pest. Altit. ca. 400 m. Leg.: Timkó, Gy. (04.1912) (BP 45160, BP 72545, BP 84575) (rev. Kärnefelt 1977) [FHE 1914, KäRNEFELT 1979, VERSEGHY 1994]. - In querceti herbidis muscosis montis "Nagykopaszhegy" prope pagum Nagykovácsi, comit. Pest. Altit. ca. 400 m. Leg.: Timkó, Gy. (04.1912) (BP 77736 as f. angustata (Hepp)) (rev. Kärnefelt 1977) [FHE 1914, Verseghy 1994]. - Ad terram calcaream inter herbas et muscos montis "Nagykopaszhegy" prope pagum Nagykovácsi, comit. Pest. Alt. ca. 400-450 m. s. m. Leg.: Timkó, Gy. (28.04.1912) (BP 24856 as f. angustata) [Tim Kó 1925, Verseghy 1994]. - Földön mohás, füves helyen Megalodus mészkőből álló hegyen, tölgyerdő nyílásában. Nagykopaszhegy ca 400-450 m. Nagykovácsi mel., Pest vm. Leg.: Kümmerle, J., Szurák, J., Timkó, Gy., Fóriss, F. (28.04.1912) (BP 24691 as f. angustata) (rev. Kärnefelt 1977) [Verseghy 1994]. - Kopár földön a Kopasztető oldalában (a vadúton) Nagykovácsi mellett, ca. 400 m. magasban. Leg.: Fóriss, F. (27.04.1912) (BP 95535) [Verseghy 1994].

Bükk Mts: Com. Borsod. Montium Bükk: Ómassa, in monte Magaskö 656. Substr.: truncos vetustos Quercus. Alt.: 650 m. s. m. Leg.: Fóriss, F. 19674 (16.04.1939) (BP 55460 as var. erinacea Schaer.).

Kőszeg Mts: Cák-Vörös kereszt, mészkerülö tölgyesben. Obs.: Vida, G. (1959, tab. in Jakucs 1965) [Jakucs 1965, LöKös et al. 1997].

Mátra Mts: Mátrafüred: Csurgó-patak-völgy északi oldalon, $450 \mathrm{~m}$. Leg.: Kiszelyné-Vámosi, A. (EGR?) [Kiszelyné-Vámosi 1983, Verseghy 1994]. - Mátrafüred: Pipis-hegy, 300 m. Leg.: Kiszelyné-Vámosi, A. (EGR?) [KISZELYNé-VÁmosi 1983, VersegGH 1994].

Pilis-Visegrád Mts: Köves földön fủ között. Dobogókő ca 700 m. Hutaszentlélek mel., Pest vm. Leg.: Kümmerle, J., Timkó, Gy., Fóriss, F. (15.08.1914) (BP 24855 as f. angustata) [Tiмкó 1925 as var. crispa, Verseghy 1994]. - Comit. Pest. (in limite Com. Esztergom). Pilisszentkereszt, a Dobogókő cserjés hegyirétjén, a kétbükkfanyergi út mellett, a Hoffmann forrási út elágazásánál, Dicranum Müblenbeckii alkotta mohagyepben. Leg.: Boros, Á. (12.05.1918) (EGR). - Comit. Esztergom. In pratis montanis montis Dobogókő supra pagum Dömös, versus "Kétbükkfanyereg”. Alt. ca. 700 m. sm. Leg.: Boros, Á. (30.09.1919) (BP 45165) (rev. Kärnefelt 1977) [Verseghy 1994].

Transdanubian Hills (Belső-Somogy): Comit. Somogy. In arenosis inter pag. Nagybajom et Kutas. Alt. 160 m. s. m. Leg.: Boros, Á. (01.07.1923) (BP 24684 as f. vulgaris) (rev. Kärnefelt 1977) [BOROS 1925].

Sopron Mts: Sopronii in montibus in terra. Leg.: Résely, M. (without date) (BP 24739) (rev. Kärnefelt 1977) [VERSEGHY 1994].

Vasi-Hegyhát: Ostffyasszonyfa mellett, autóút közelében, talajon, gyepben. Leg.: Kiss, T., Facsar, G. (24.08.1983) (SZO 95, SZO 96, SZO 262).

Vendvidék: Szakonyfalu: Szakonyi-erdő, Ágnes-forrás környékén, nyiladék csarabos talaján. Leg.: Farkas, E., Lőkös, L. and Tibell, L. (08.04.1994). (BP) [LöKös and FARKAS 1998]. 